\title{
The association between S100A13 and HMGA1 in the modulation of thyroid cancer proliferation and invasion
}

Jing Zhong ${ }^{1 \dagger}$, Chang Liu ${ }^{1,2+}$, Ya-jun Chen ${ }^{1,3}$, Qing-hai Zhang ${ }^{1}$, Jing Yang ${ }^{4}$, Xuan Kang ${ }^{1}$, Si-Rui Chen ${ }^{1}$, Ge-bo Wen ${ }^{1,4}, \mathrm{Xu}-\mathrm{yu} \mathrm{Zu}^{1 *}$ and Ren-xian Cao ${ }^{1,4^{*}}$

\begin{abstract}
Background: S100A13 and high mobility group A (HMGA1) are known to play essential roles in the carcinogenesis and progression of cancer. However, the correlation between S100A13 and HMGA1 during cancer progression is not yet well understood. In this study, we determined the effects of S100A13 on HMGA1 expression in thyroid cancer cells and examined the role of HMGA1 in thyroid cancer progression.
\end{abstract}

Methods: Stable ectopic S100A13 expression TT cellular proliferation was evaluated by nude mice xenografts assays. The effect of lentivirus-mediated S100A13 knockdown on thyroid cancer cellular oncogenic properties were evaluated by MTT, colony formation assays and transwell assays in TPC1 and SW579 cells. The effect of siRNA-mediated HMGA1 knockdown on thyroid cancer cellular proliferation and invasion were evaluated by MTT, colony formation assays and transwell assays. The tissue microarray was performed to investigate the correlation between S100A13 and HMGA1 expression in tumor tissues.

Results: The ectopic expression of S100A13 could increase tumor growth in a TT cell xenograft mouse model. Moreover, lentivirus-mediated S100A13 knockdown led to the inhibition of cellular oncogenic properties in thyroid cancer cells, and HMGA1 was found to be involved in the effect of S100A13 on thyroid cancer growth and invasion. Furthermore, siRNA-mediated HMGA1 knockdown was proved to inhibit the growth of TPC1 cells and invasive abilities of SW579 cells. Clinically, it was revealed that both S100A13 and HMGA1 showed a higher expression levels in thyroid cancer cases compared with those in matched normal thyroid cases $(P=0.007$ and $P=0.000) ;$ S100A13 and HMGA1 expressions were identified to be positively correlated $(P=0.004, R=0.316)$ when analyzed regardless of thyroid cancer types.

Conclusions: This is the first report for the association between HMGA1 and S100A13 expression in the modulation of thyroid cancer growth and invasion. Those results would provide an essential insight into the effect of S100A13 on carcinogenesis of thyroid tumor, rending S100A13 to be potential biological marker for the diagnosis of thyroid cancer.

Keywords: S100A13, HMGA1, RNA interference, Proliferation, Invasion, Thyroid cancer

\section{Background}

S100A13 is a small calcium $\left(\mathrm{Ca}^{2+}\right)$-binding protein which belongs to the $\mathrm{S} 100$ family. It is characterized by

\footnotetext{
*Correspondence: zuxuyu0108@hotmail.com; caorenxian@hotmail.com ${ }^{\dagger}$ Jing Zhong and Chang Liu contributed equally to this work

${ }^{1}$ Institute of Clinical Medicine, The First Affiliated Hospital of University of South China, 421001 Hengyang, Hunan, People's Republic of China Full list of author information is available at the end of the article
}

its specificity for diverse forms of cancer [1-3]. S100A13 could regulate secretion of FGF1 and IL1 $\alpha$ and could be a marker for vessel density and on a cellular level $[4,5]$. In addition S100A13 is also involved in cell cycle progression and differentiation, including cytokine and NF- $\mathrm{kB}$ signalling, suggesting that S100A13 may be related to increased aggressiveness of melanoma tumours $[6,7]$. Several studies reported positive correlation between 
the elevated expression of S100A13 and risk of relapse and status of melanoma patients at follow-up, indicating that S100A13 may play a crucial role in melanoma chemoresistance $[8,9]$. Moreover, S100A13 was found to be involved in the invasiveness of lung cancer cell lines [10], and also was detected in tumor cells circulating in blood of patients with metastatic cancer [11], indicating that this protein may be considered as a predictor of cancer metastases. Recently, a study on cystic papillary thyroid carcimoma (cPTC) confirmed a significant up-regulation of cytokeratin 19 and S100A13 in cPTC compared to benign lesions, suggesting their possible use in fine needle aspiration biopsy based preoperative diagnostics of cystic thyroid lesions [12]. With multiplexed and targeted mass spectrometry method, S100A13 was also found to be elevated in papillary thyroid carcinoma (PTC) compared to normal tissue, suggesting that S100A13 may be considered as a novel candidate PTC biomarker [13].

High mobility group A (HMGA1) is an architectural transcription factor that encodes a nonhistone chromatin protein. Two isoforms, HMGA1a and HMGA1b are produced which do not show direct transcriptional regulation activities, but they regulate the transcriptional activity of several genes by altering the chromatin structure [14-16]. The expression of HMGA1 is absent or present only at low level in normal cell and adult tissues but are elevated in embryonic cells [17] and many malignant neoplasias, including breast [18], pancreas [19], lung [20], ovary [21], colon [22] and thyroid carcinomas [23]. HMGA1 has been confirmed to associate with the initiation and progression of diverse types of tumors [24-27]. HMGA1 has also been reported to correlate with the presence of metastasis and reduced survival [28], and could be a poor prognostic marker.

In this study, we examined the effects of S100A13 and HMGA1 on thyroid cancer progression. The results suggest that HMGA1 was involved in the effect of S100A13 on thyroid cancer growth and invasion by modulating the expression of Snail and E-cadherin. In addition, a tissue microarray revealed that higher expressions of both S100A13 and HMGA1 were observed in thyroid cancer cases compared with that in normal thyroid cases. Statistical analysis also confirmed that S100A13 and HMGA1 expressions were positively correlated. This study establish the first link between S100A13 and HMGA1 in thyroid cancer, providing further evidence of the pivotal role of HMGA1 in thyroid cancer progression.

\section{Methods}

\section{Cell culture}

Human thyroid cancer cell line TT, TPC1 and SW579 were purchased from American Type Culture Collection (USA). After thawing, TT cells were cultured in F12 K
(N3520; Sigma, USA) medium supplemented with $10 \%$ fetal bovine serum (Gibco, USA) and $\mathrm{NaHCO}_{3} 2.5 \mathrm{~g} / \mathrm{L}$ at $37{ }^{\circ} \mathrm{C}$ in a humidified atmosphere containing $5 \% \mathrm{CO}_{2}$. TPC1 cells were cultured in DMEM medium supplemented with $10 \%$ fetal bovine serum at $37^{\circ} \mathrm{C}$ in a humidified atmosphere containing $5 \% \mathrm{CO}_{2}$. SW579 cells were cultured in L15 medium supplemented with $10 \%$ fetal bovine serum at $37^{\circ} \mathrm{C}$ in a humidified atmosphere without $\mathrm{CO}_{2}$. After three passages, cells were used for viral infection.

\section{Western blot analysis}

Total cell lysates were lysed on ice for $30 \mathrm{~min}$. Soluble proteins $(20 \mu \mathrm{g})$ were probed with anti-S100A13, anti-HMGA1, anti-Snail, and anti-E-cadherin antibodies (1:500, Abcam). Loading variations were normalized against $\beta$-actin, which was identified by anti- $\beta$-actin monoclonal antibody (1:1000, Abcam).

\section{Construction and screening of lentiviral vectors harboring S100A13-specific siRNA}

The siRNA sequences targeting to human S100A13 gene (GenBank accession No. NM_001024210) were selected: Target1: ATGAGTACTGGAGATTGAT; Target2: CTCGGAGCTCAAGTTCAAT; and Target3: TGGGCTCTCTTGATGAGAA. Three pairs of complementary oligonucleotides were then designed (Additional file 1: Table S1). The stem-loop oligonucleotides were synthesized and cloned into a lentivirus-based vector carrying the green fluorescent protein (GFP) gene (pGCSIL-GFP, Genechem, Shanghai, China). A universal sequence (PSC-NC: TTCTCCGAACGTGTCACGT) was used as a negative control for RNA interference. Lentiviral particles were prepared as previously described [29].

Three siRNA-carrying lentiviral vector constructs were used to infect TPC1 at a multiplicity of infection (MOI) of 20 (low MOI) and 40 (high MOI). Three days after infection, GFP expression was detected to calculate the infection efficiency. Five days after infection, cells were harvested. Real-time reverse transcription polymerase chain reaction (RT-PCR) was performed to determine S100A13 knockdown efficiency and screen for the siRNA with the highest knockdown efficiency which was then used for subsequent experiments.

\section{RNA isolation and reverse transcription PCR (RT-PCR)}

The SW579 were treated with Scramble RNA or HMGA1 siRNA $(40,80,160 \mathrm{nM})$, and maintained in culture medium for $48 \mathrm{~h}$. Total RNA was extracted from the SW579 cells using TRIzol reagent (Invitrogen) and the total RNA was reverse transcribed into cDNA using the first-strand synthesis kit (Gibco-BRL, Carlsbad, CA, USA). The mRNAs of HMGA1, E-cadherin, Snail and 
$\beta$-actin were amplified using the primers (Additional file 2: Table S2). The gene-specific primers were amplified with a denaturation step $\left(95^{\circ} \mathrm{C}\right.$ for $\left.2 \mathrm{~min}\right)$, followed by 35 cycles of denaturation $\left(95^{\circ} \mathrm{C}\right.$ for $\left.30 \mathrm{~s}\right)$, annealing $\left(55^{\circ} \mathrm{C}\right.$ for $30 \mathrm{~s})$ and extension $\left(72{ }^{\circ} \mathrm{C}\right.$ for $\left.50 \mathrm{~s}\right)$. Samples from three separate experiments were analyzed in duplicate. The results from RT-PCR were expressed using $\beta$-actin as a reference.

\section{Cell proliferation and colony formation assays}

For cell proliferation assays, cells were seeded in a 96-well plate (2000 cells/well) and counted using an automated cell counter (Nexcelom Bioscience, Lawrence, MA, USA). For colony formation assay, cells were seeded in a 12-well plate (400 cells/well) and maintained for 8 days. Each experiment was carried out in triplicate and performed at least twice.

\section{Cell invasion assays}

For the invasion assays, 10,000 cells were resuspended in serum-free medium and placed in the upper chamber of a 24-well Matrigel ${ }^{\mathrm{TM}}$ Invasion Chamber (BD Biosciences, SanDiego, CA, USA) coated with Matrigel. Cell invasion was calculated as the percentage of total cells that had invaded the bottom chamber containing complete medium with serum.

\section{Scratch-wound assays}

For the scratch-wound assays, cells were transiently transfected with shRNA vectors and grown to confluence. A central linear wound area was carefully created by scraping the cell monolayer with a sterile $200 \mu \mathrm{l}$ pipette tip, and images were taken after $24 \mathrm{~h}$. Bars represent as the mean percentage of wound closure relative to the initial wound area.

\section{Tumour xenografts}

Four-week-old BALB/c female nude mice were fed on the super-clean biological laminar flow shelf for 1 week. All of the in vivo experimental protocols were approved by the Animal Care Committee of South China University. The details of tumour xenografts assay were performed as described previously [30].

\section{Transient transfection and luciferase activity assay}

Transient gene delivery was carried out to assess the effect of HMGA1 on Snail and E-cadherin promoter activity in SW579 cells as described previously [31]. A luciferase assay kit (Promega) was used to measure the reporter activity according to the manufacturer's instructions. Luciferase activity was normalized by using a Renilla luciferase internal control.

\section{Tissue microarray and immunohistochemical analysis}

The tissue microarray (TH8010, US Biomax) consisting 70 thyroid cancer cases and 10 normal cases was utilized, and was histologically interpretable and analyzed for the correlation with clinicopathological parameters. IHC staining was performed as detailed in our previous studies [30]. The mouse monoclonal S100A13 (1:25; ab55701, Abcam) antibody and the rabbit polyclonal HMGA1 antibody (1:150; ab4078, Abcam) were used.

\section{Statistical analysis}

All experiments were performed with three replicates and the results were expressed as the mean \pm S.E.M or mean \pm SD. Statistical analysis was done using SPSS, version 13.0. A statistical association between clinicopathological and molecular parameters was tested, using non-parametrically two-tailed Mann-Whitney U test. $P$ values $<0.05$ were considered significant. Spearman's rank-correlation coefficients were used to assess the relationship between S100A13 and HMGA1 expression.

\section{Results \\ S100A13 overexpression increases tumor growth in a TT cell xenograft mouse model}

It was previously revealed that S100A13 had essential roles in various cancer, we therefore exploited whether S100A13 was involved in the development of thyroid cancer. Using Stable cell lines with the GFP and S100A13-GFP, we found that overexpression of S100A13 in the transfected thyroid cancer TT cells markedly increased cells proliferate ability, and decreased population percentage of $G_{0} / G_{1}$ period compared to those cells with either GFP or untransfected TT cells [32]. To further examine the effects of S100A13 on cell proliferation in vivo, we transplanted three types of thyroid tumours cells developed from TT cells (S100A13-GFP, GFP and TT) into nude mice. Growth of the implanted tumours was measured in mice $(n=5$ for each group) over a period of 7 weeks. Overexpression of S100A13 dramatically increased the size and weight of tumors compared to those engrafted with GFP cells or with untransfected TT cells $(P<0.05$ and $P<0.01$, Fig. 1a, b), but the difference between the GFP cells group and untransfected TT cells group was not significant. Cyclin E, one of the key gene of cell cycle was found to be upregulated in S100A13-GFP cells (Fig. 1c), indicating that it might be involved in S100A13 induced cell proliferation. HMGA1, an architectural transcription factor associating with the initiation and progression of diverse types of tumors, also was found to be upregulated in S100A13-GFP cells (Fig. 1c). Those data suggest that overexpression of S100A13 enhances oncogenic properties of thyroid cancer cells in vitro and in vivo. 
a

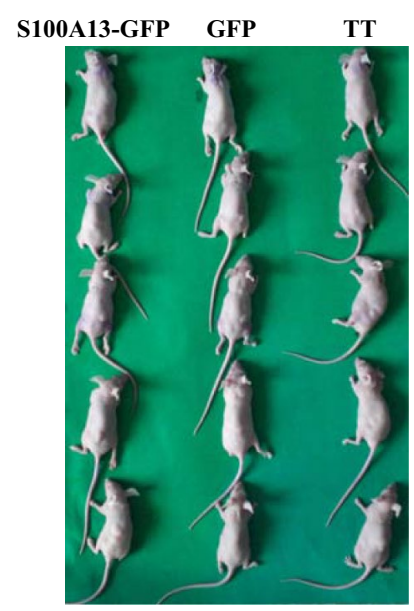

b

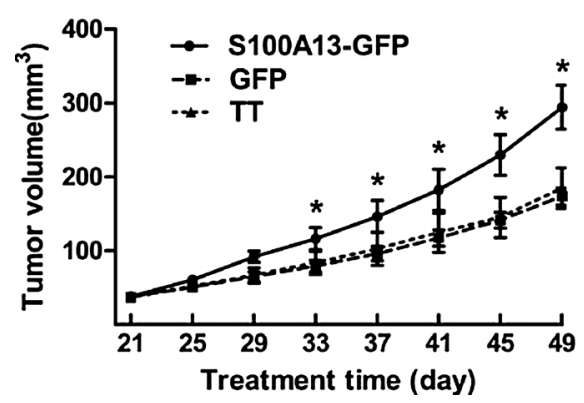

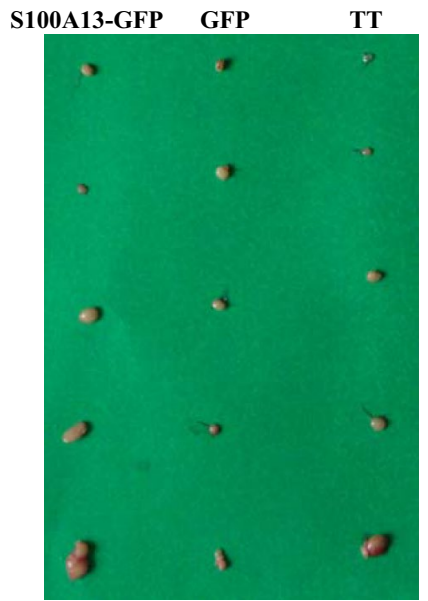

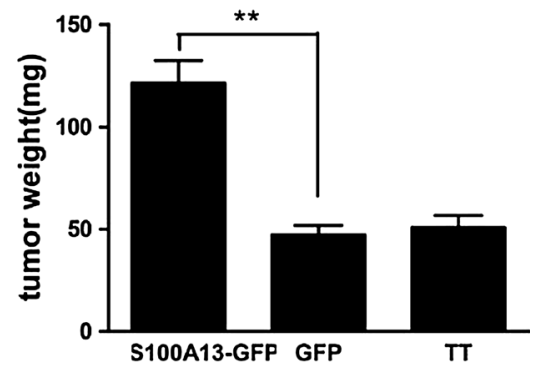

c

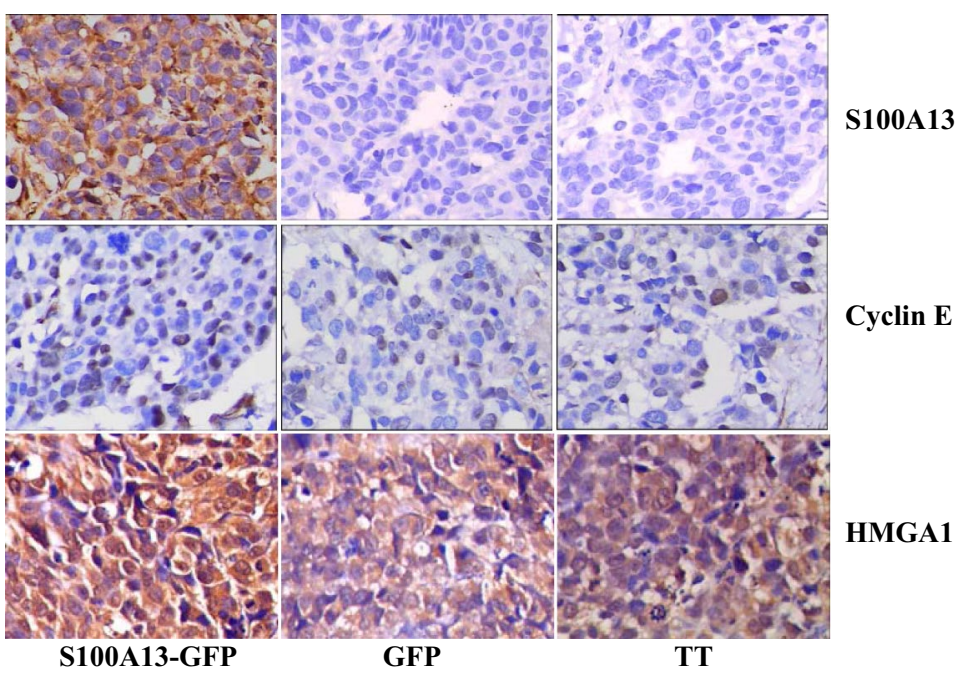

Fig. 1 S100A13 overexpression increases tumor growth in a TT cell xenograft mouse model. a S100A13-GFP, GFP or TT groups cells were transplanted into ovariectomized athymic mice. Left mice appearances in different treated groups. Right tumor appearances in different treated groups. b Left increased tumor volume in S100A13 overexpression mice. Tumours were measured weekly using a vernier calliper and the volume was calculated according to the formula: $\pi / 6 \times$ length $\times$ width $^{2}$. Each point represents the mean \pm SD for different animal measurements $(n=5)\left(^{*} P<0.05\right)$. Right increased tumor weight in S100A13 overexpression mice (**P $<0.01)$. c Detection of proteins expression by immunohistochemical assay of tumor tissues in nude mice in different treated groups (streptavidin biotin complex $\times 400$ ) 


\section{S100A13 knockdown inhibits in vitro cell growth in the least/non-invasive cell line}

S100A13/GV248RNAi-LV-1 was transfected into thyroid cancer TPC1 cells and SW579 cells, individually. The infection efficiencies of these lentiviral vectors were all above $90 \%$ as revealed by fluorescence microscopy (Fig. 2a, b). Real-time RT-PCR assay showed that all three constructs, whether they were used at a high or low MOI, could significantly downregulate S100A13 gene expression in TPC1 cells (Additional file 3: Figure S1). As shown in Fig. 3a, the MTT assay showed that TPC1 cell proliferation was significantly inhibited in the S100A13 knockdown group as compared to those of the control group and the NC group at the fifth days $(P<0.05)$, however,
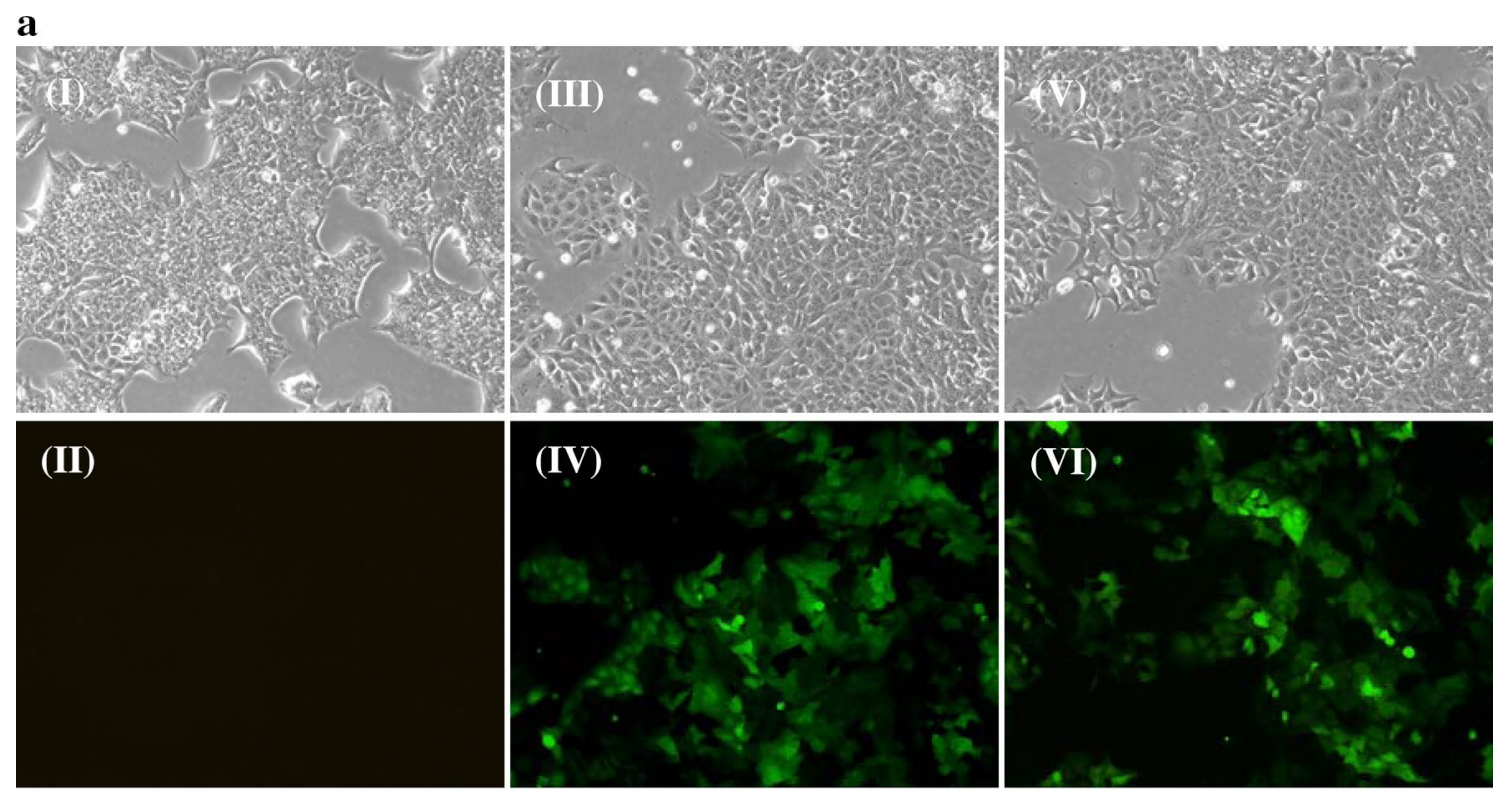

b
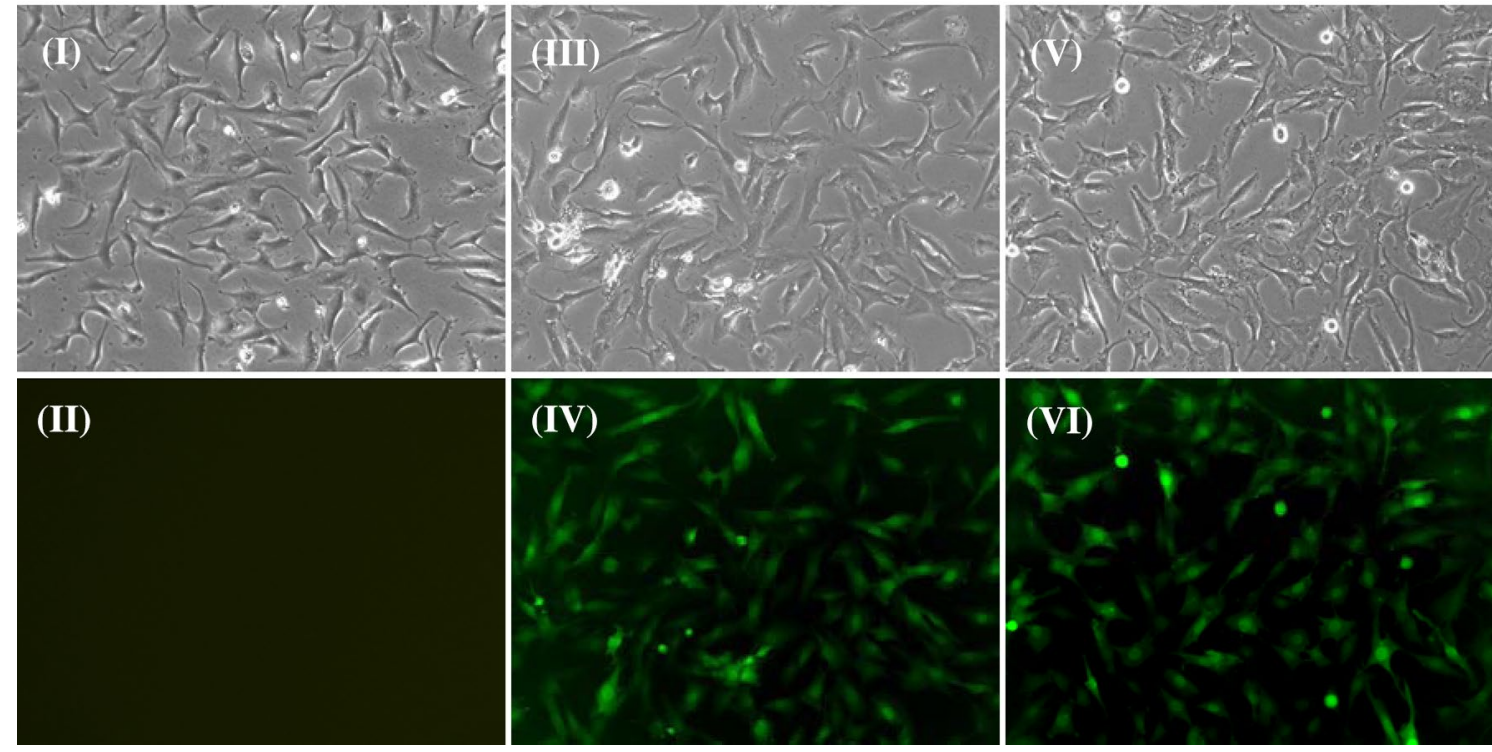

Fig. 2 a Fluorescence microscopy examination of the infection efficiencies of different lentiviral vectors in TPC1 cells (magnification $\times 100)$. I, TPC1 cells without lentiviral infection (Con group) in the light microscope; II, TPC1 cells of Con group in the fluorescence microscope; III, TPC1 cells were infected with negative lentivirus NC/GV248RNAi-LV (NC group) in the light microscope; IV, TPC1 cells of NC group in the fluorescence microscope; V, TPC1 cells were infected with lentivirus S100A13/GV248RNAi-LV\#1 RNAi (KD group) at a high MOI in the light microscope; VI, TPC1 cells of KD group at a high $\mathrm{MOI}$ in the fluorescence microscope. b Fluorescence microscopy examination of the infection efficiencies of different lentiviral vectors in SW579 cells (magnification $\times 100$ ). The description of panels was similar with that in $\mathbf{a}$ 


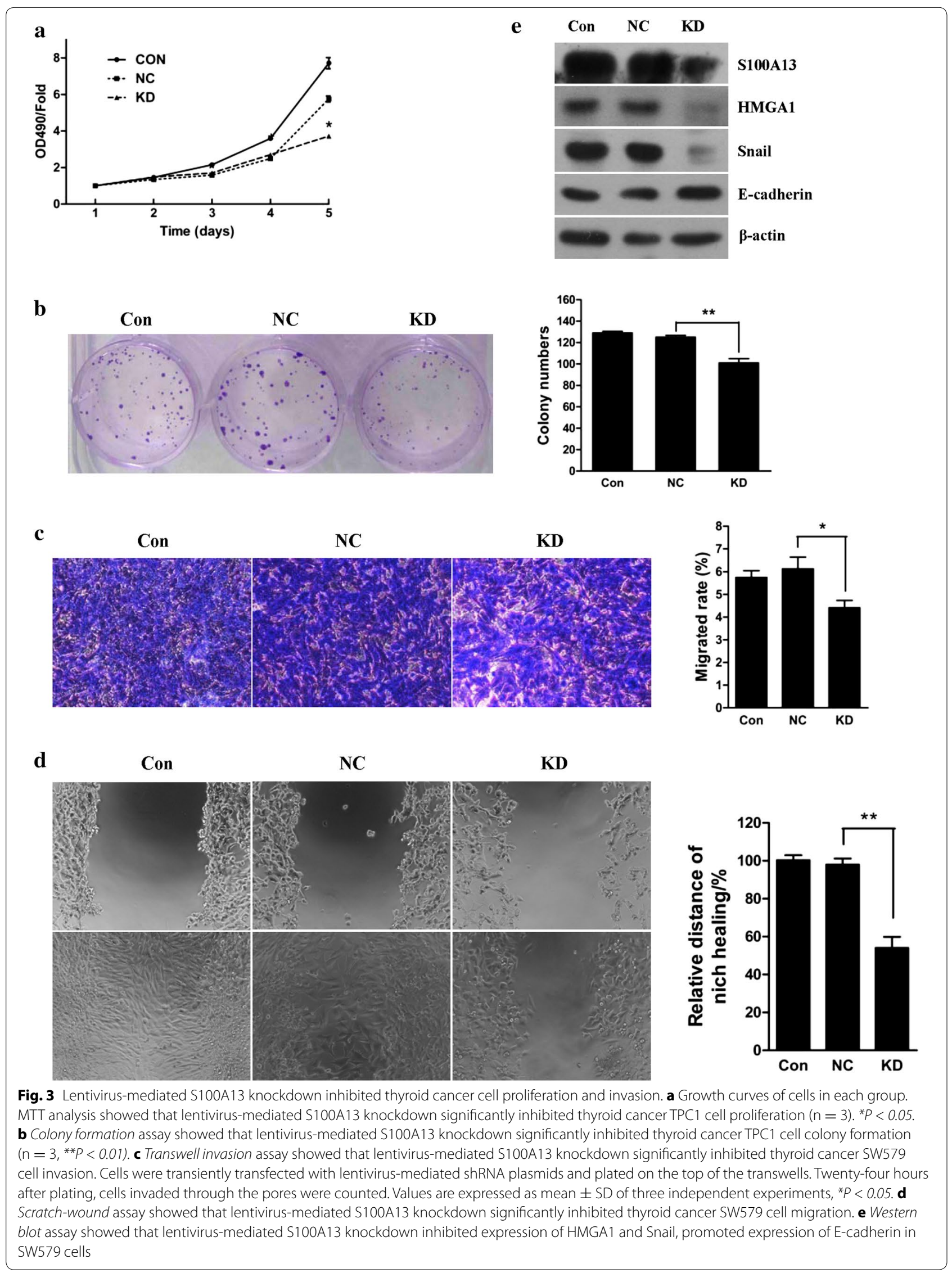


the SW579 cell proliferate ability of S100A13 knockdown group showed no significant difference compared to those of the control group and the $\mathrm{NC}$ group at the indicated time points (Additional file 4: Figure S2a).

Colony formation assay showed that the number of formed colonies from TPC1 cells with lentivirus-mediated S100A13 knockdown was markedly decreased compared to those of the control group and the NC group (Fig. 3b, $P<0.01$ ). Whereas, the number of formed colonies of SW579 cells carrying with lentivirus-mediated S100A13 knockdown showed no significant difference to those of the control group and NC group (Additional file 4: Figure S2b). Those results indicated that S100A13 knockdown could inhibit the cell proliferation and colony formation of the least/non-invasive thyroid cancer TPC1 cells, but show no obvious effect on the proliferate ability of invasive thyroid cancer SW579 cells.

\section{S100A13 knockdown inhibits the invasive and migration capabilities through decrease the expression of HMGA1 in thyroid cancer SW579 cells}

To determine if S100A13 knockdown was able to affect the invasion properties of thyroid cancer TPC1 cells and SW579 cells, the transwell invasion assay and scratchwound assay were performed. As shown in Fig. 3c, compared to those of the control group and the $\mathrm{NC}$ group, the invasion rate of SW579 cells in the S100A13 knockdown group decreased significantly $(P<0.05)$. As well as the result of invasion assay, the migration capability of the S100A13 knockdown group decreased significantly compared to those of the control group and the NC group (Fig. 3d, $P<0.01$ ). The invasive and migration capabilities showed no significant difference between the control group and the NC group (Fig. 3c, d). The thyroid cancer TPC1 cells, however, showed no invasive capability even in the control group, and the migration capability of TPC1 cell with the S100A13 knockdown group showed no obvious difference compared to those of the NC group (Additional file 5: Figure S3). To determine if S100A13 knockdown was able to affect the expressions of invasion associated factors, the western blot was performed. As shown in Fig. 3e, S100A13 knockdown could lead to the downregulation of HMGA1 and Snail and the upregulation of E-cadherin in SW579 cells. Moreover, the ectopic S100A13 expression could increase both HMGA1 and Snail mRNA expressions (Additional file 6: Figure S4) and enhance the promoter activities (Additional file 7: Figure S5).

\section{HMGA1 knockdown inhibits in vitro cell growth and invasion}

It was reported that HMGA1 overexpression could promote the growth and invasion of cancer cells [24-27]. To address the effect of HMGA1 on thyroid cancer cells, the
HMGA1 targeting siRNA were used. As shown in Fig. 4a and b, HMGA1 silence in TPC-1 cell could inhibit the cell proliferation and decrease the colony formation ability. Furthermore, it was revealed that the siRNA induced HMGA1 could lead to the downregulation of Snail and upregulation of E-cadherin in both mRNA or protein levels in SW579 cells (Fig. 4c), resulting in the decrease of invasive abilities of thyroid cancer SW579 cells (Fig. 4d, $P<0.01$ ).

To further clarify the mechanism by which HMGA1 affect the expression of Snail or E-cadherin in SW579 cells, luciferase reporter assay was performed. It was demonstrated that HMGA1 could enhance the promoter activities of Snail gene and inhibit the promoter activities of E-cadherin in a dose-dependent manner (Fig. 5a, b). Those results indicate that HMGA1 might affect the expression of E-cadherin and Snail by regulating the promoters' activities in SW579 cells.

\section{S100A13 correlates with HMGA1 expression in thyroid carcinoma}

To further indentify the relationship between S100A13 and HMGA1 expression in thyroid cancer, tissue microarray (TH8010, US Biomax), consisting of 70 thyroid cancer cases and 10 normal cases was used, and the clinicopathologic data were available in Table 1 . The immunohistochemistry analysis showed that S100A13 was stained in $94.3 \%$ of thyroid tumors, predominantly in nuclear with faint cytoplasmic staining, and was stained in $60.0 \%$ in normal thyroid tissue $(P=0.007$, Table 2$)$. HMGA1 was stained in $98.6 \%$ of thyroid tumors, predominantly in nuclear with faint cytoplasmic staining, and was stained in $60.0 \%$ in normal thyroid tissue $(P=0.000$, Table 2$)$. S100A13 and HMGA1 immunostainings of tumor and normal tissue of representative cases of thyroid carcinoma are shown in Fig. 6. Furthermore, S100A13 and HMGA1 expressions were found to be positively correlated $(r=0.316, P=0.004)$, when analyzed regardless of thyroid cancer types (Table 3 ). S100A13 expressions in thyroid carcinoma did not show a statistically significant correlation with patient age and nodal metastasis of the tumor (Table $1, P>0.05$ ). However, S100A13 expression in thyroid carcinoma was shown to be more common in male than that in female, and much higher in papillary cancer compared with follicular cancer and undifferentiated cancer (Table 1, $P=0.049$ and 0.051). HMGA1 expression in thyroid carcinoma also showed a statistically significant correlation with the patient sex and tumor types (Table $1, P=0.016$ and 0.003). Those tissue microarray data confirmed that S100A13 and HMGA1 expression were positively correlated in thyroid carcinoma, and it may be involved in the progression of thyroid cancer. 


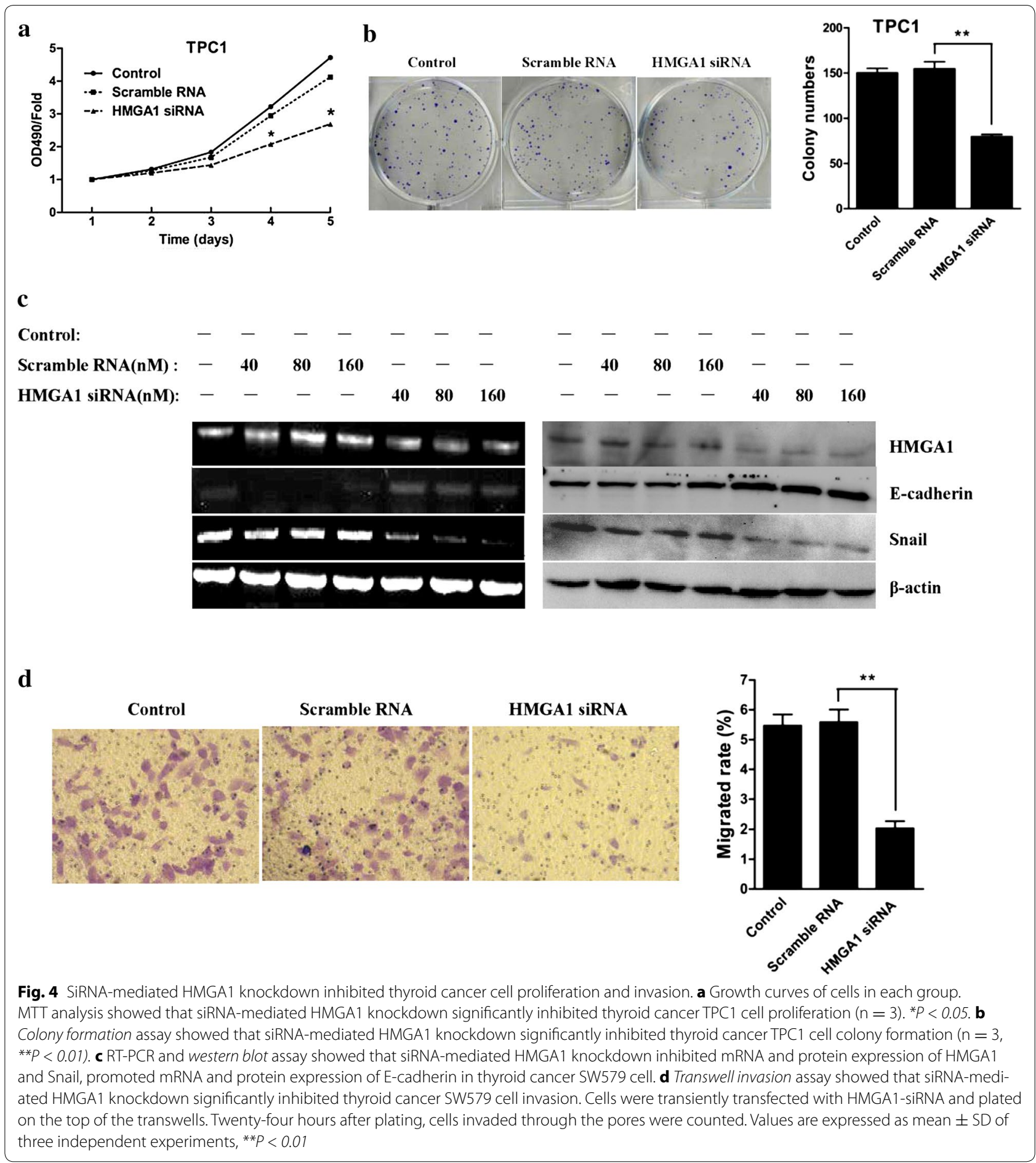

\section{Discussion}

The S100 protein family has been implicated in the regulation of a number of cellular processes such as cell growth and differentiation, cell cycle progression, phosphorylation regulation of proteins, protein secretion, organization of membrane structure and cytoskeleton dynamics [33]. Recently, increasing number of studies report that S100 family members are associated with a variety of human diseases, including neurodegeneration, inflammatory disorders and cancers [34]. In particular, S100A4, S100A6, S100A7 and S100A10 have been found to be overexpressed in some cancer types, 

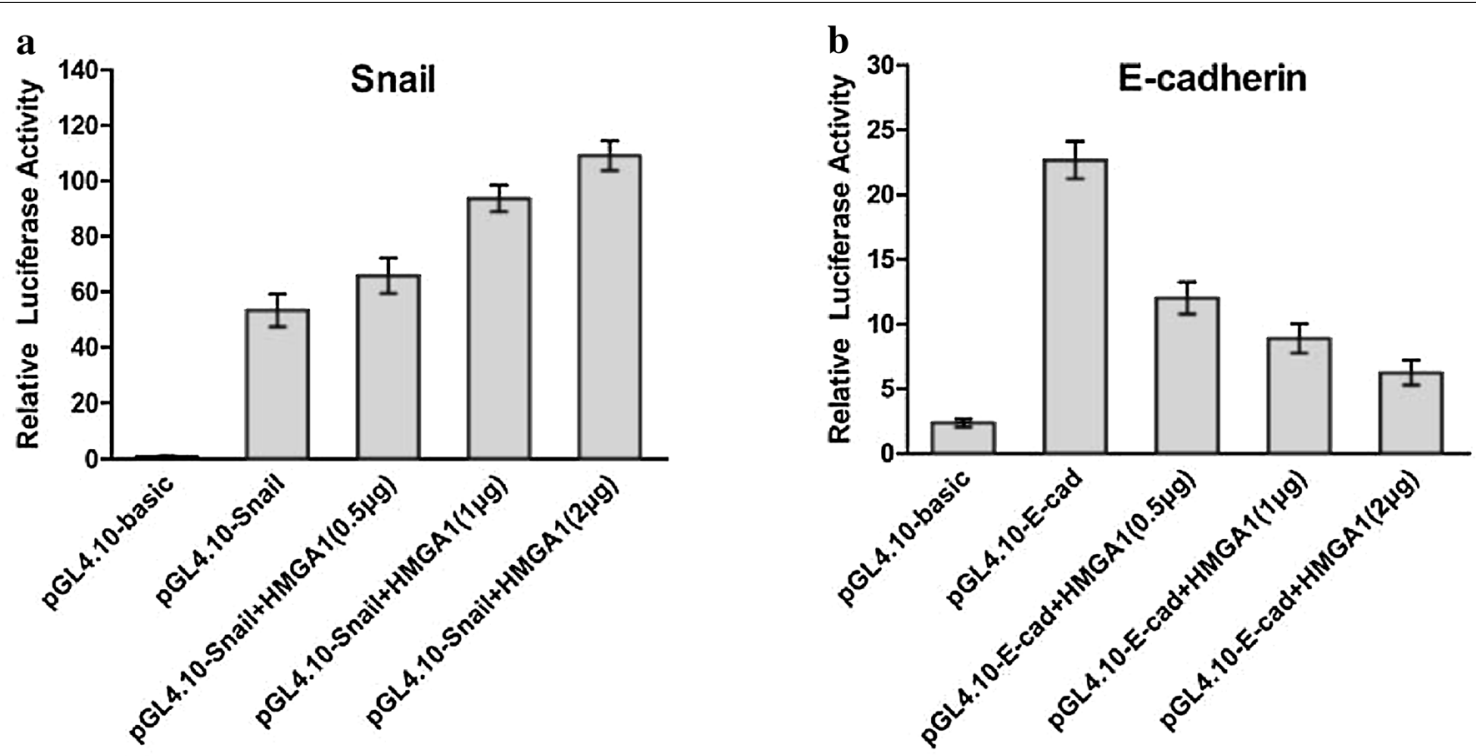

Fig. 5 HMGA1 overexpression affect Snail and E-candherin promoter activities in SW579 cell. a, b Luciferase activity assay showed that HMGA1 overexpression inhibited promoter activity of E-cadherin, promoted promoter activity of Snail in a dose-dependent manner

Table 1 Correlation of S100A13 and HMGA1 expression with clinicopathological parameters

\begin{tabular}{|c|c|c|c|c|c|c|c|c|c|c|}
\hline & \multirow[t]{2}{*}{$n$} & \multicolumn{4}{|c|}{$\mathrm{S} 100 \mathrm{~A} 13$} & \multirow[t]{2}{*}{$P$ value } & \multicolumn{3}{|c|}{ HMGA1 } & \multirow[t]{2}{*}{$P$ value } \\
\hline & & - & + & ++ & +++ & & - & + & ++ & \\
\hline Age (years) & & & & & & 0.549 & & & & 0.984 \\
\hline$>50$ & 30 & 2 & 7 & 20 & 1 & & 0 & 13 & 17 & \\
\hline$\leq 50$ & 40 & 2 & 7 & 30 & 1 & & 1 & 16 & 23 & \\
\hline Sex & & & & & & 0.049 & & & & 0.016 \\
\hline Male & 14 & 0 & 1 & 12 & 1 & & 0 & 2 & 12 & \\
\hline Female & 56 & 4 & 13 & 38 & 1 & & 1 & 27 & 28 & \\
\hline Tumor types & & & & & & 0.051 & & & & 0.003 \\
\hline Papillary & 46 & 2 & 5 & 38 & 1 & & 1 & 14 & 31 & \\
\hline Follicular & 18 & 1 & 7 & 9 & 1 & & 0 & 14 & 4 & \\
\hline Undifferentiated & 6 & 1 & 2 & 3 & 0 & & 0 & 1 & 5 & \\
\hline Node metastasis & & & & & & 0.213 & & & & 0.063 \\
\hline Positive & 17 & 0 & 2 & 15 & 0 & & 0 & 4 & 13 & \\
\hline Negative & 53 & 4 & 12 & 35 & 2 & & 1 & 25 & 27 & \\
\hline
\end{tabular}

Table 2 Expressions of S100A13 and HMGA1 in thyroid normal tissue and cancer

\begin{tabular}{|c|c|c|c|c|c|c|c|}
\hline & \multirow[t]{2}{*}{$\mathrm{n}$} & \multicolumn{2}{|l|}{ S100A13 } & \multirow[t]{2}{*}{$P$ value } & \multicolumn{2}{|l|}{ HMGA1 } & \multirow[t]{2}{*}{$P$ value } \\
\hline & & Positive & Negative & & Positive & Negative & \\
\hline Tissue types & & & & 0.007 & & & 0.000 \\
\hline Normal & 10 & 6 & 4 & & 6 & 4 & \\
\hline Tumor & 70 & 66 & 4 & & 69 & 1 & \\
\hline
\end{tabular}

and could be associated with aggressive cancer phenotype [35-39]. However, the molecular mechanisms of S100 proteins implicating in tumor progression remain to be elucidated. S100A13 is the member of S100 family, and it has been shown to be involved in the nonclassical export of signal-peptideless proteins, including fibroblast 


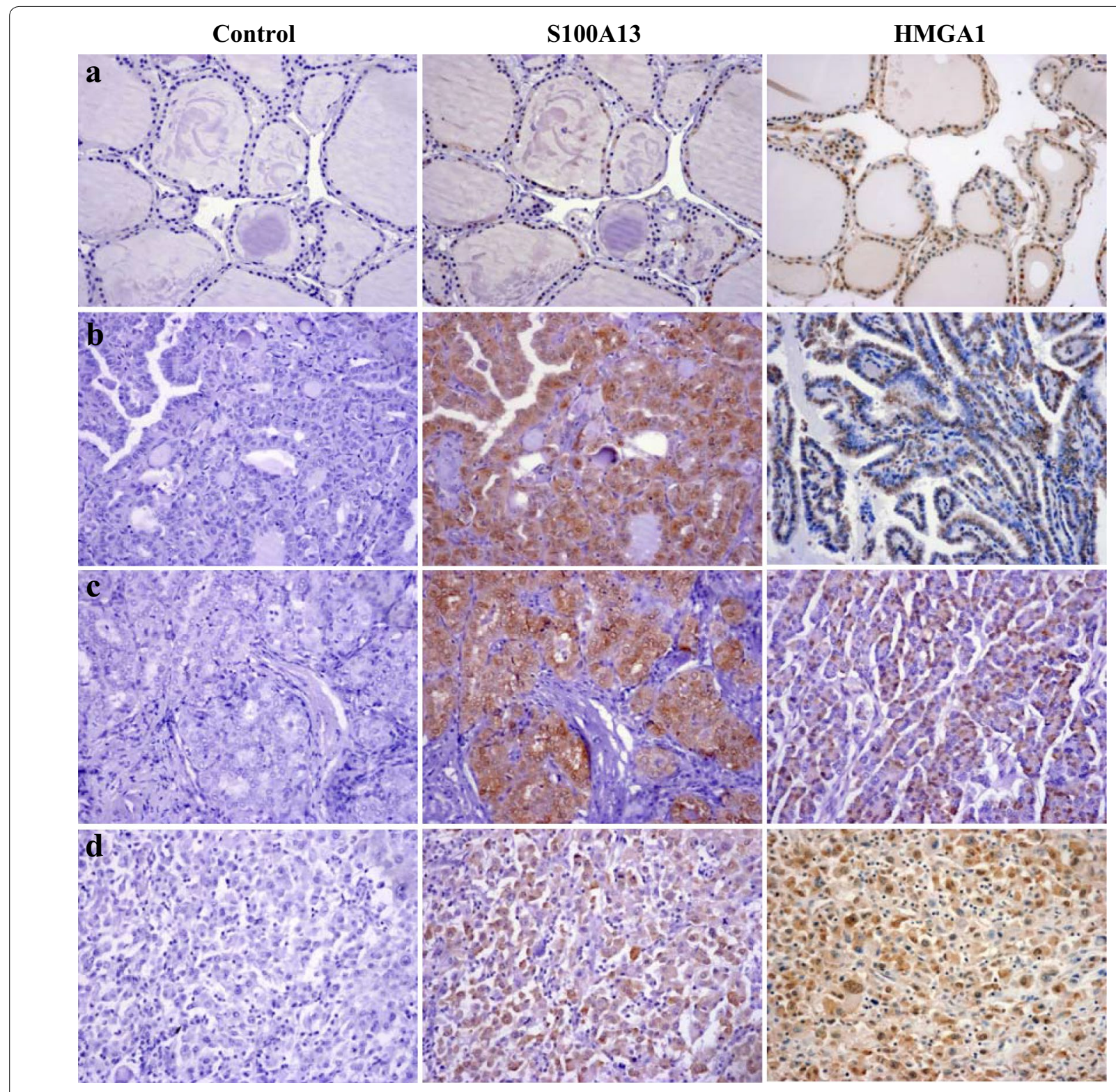

Fig. 6 S100A13 and HMGA1 protein expression show a positive correlation in thyroid carcinoma (images in original magnification, $\times 200$ ). a Normal thyroid tissue, $\mathbf{b}$ thyroid papillary carcinoma, $\mathbf{c}$ thyroid follicular carcinoma, $\mathbf{d}$ thyroid undifferentiated carcinoma

Table 3 Correlation of S100A13 and HMGA1 expression

\begin{tabular}{lccccc}
\hline & $\mathbf{n}$ & HMGA1 & & Spearman (r) \\
\cline { 3 - 6 } & & - & + & ++ & \\
\hline S100A13 & 4 & 1 & 2 & 1 & 0.316 \\
- & 14 & 0 & 6 & 8 & \\
+ & 52 & 0 & 21 & 31 & \\
$++\sim++$ & & 0 & & \\
\hline
\end{tabular}

growth factors, interleukin $1 \alpha$, and synaptotagmins $[40,41]$. Recent data showed that S100A13 is related to inflammatory functions [5]. It was also reported that
S100A13 expressed differentially during brain development, suggesting that it may play a role in nervous system function [41-43]. Increasing evidences also showed the 
association between S100A13 and tumourigenesis, indicating the role of S100A13 in initial and progression in diversity of cancer $[6,7,9-11]$.

In this study, experiments were performed to determine the effects of S100A13 on cell proliferation, and we demonstrated that the ectopic expression of S100A13 could enhance cellular proliferation of thyroid cancer TT cells in vivo. To further define the effect of S100A13 on other thyroid cancer cells, three lentivirus-mediated S100A13 gene targeting shRNA (KD1, KD2 and KD3) were used to silence the expression of S100A13 in thyroid cancer TPC1 and SW579 cells. It was revealed that the downregulation of S100A13 could inhibit the TPC1 cells growth in vitro and lead to the decrease of invasive and migration ability of SW579 cell line in vitro. Those findings provide evidences for the involvement of S100A13 in the modulation of thyroid cancer cell proliferation and invasion. It was reported that the IL1 $\alpha$-S100A13 complex plays an important role in cell proliferation and angiogenesis, and would be an effective strategy to inhibit a wide range of cancers [41]. It was also reported that S100A13 increased in human astrocytic gliomas, in which it correlates with VEGF-A expression, microvessel density and tumor grading [7] and it is also associated with a more aggressive, invasive phenotype in lung cancer-derived cell lines [10]. Moreover, S100A13 was detected in tumor cells circulating in blood of patients with metastatic cancer, indicating that S100A13 could be considered as a predictor of metastases [11].

Intriguingly, the siRNA induced S100A13 downregualtion was found to cause the decreased expression of HMGA1 and Snail and increased E-cadherin expression in SW579 cells, indicating the involvements of HMGA1, Snail and E-cadherin in S100A13 induced celluar proliferation and invasion. Recent study reports silencing HMGA1 could block proliferation, migration and invasion of triple negative breast cancer MDA-MB-231 cells. Mesenchymal genes (Vimentin, Snail) are repressed, while E-cadherin is induced in the HMGA1 knock-down cells [18]. In our study, the downregulation of HMGA1 was further confirmed to be able to decrease and increase the expression of Snail and E-cadherin respectively, resulting in the suppression of TPC1 cells proliferation and SW579 cells invasion. Those results indicate that S100A13 and HMGA1 show the consisitent effects on the proliferation and invasion of thyroid cancer cells.

The higher expressions of both S100A13 and HMGA1 were observed in thyroid cancer tissues compared with that in normal thyroid tissues through the analysis of tissue microarray, indicating that the elevated expression of S100A13 and HMGA1 in thyroid cancer tissue might play a role in the initiation and progression of thyroid cancer. Further analysis to the tissue microarray data unraveled a positive correlation between S100A13 and
HMGA1 expression $(P=0.004)$ regardless of thyroid cancer types, which is consistent with the results from cells models, suggesting that S100A13 may be of importance in regulating HMGA1 expression in human thyroid cancer, and that S100A13 might be responsible for the increased ability of proliferation and invasion in thyroid cancer cells. Moreover, the expressions of S100A13 and HMGA1 in thyroid carcinoma were shown to be associated with the patient sex and tumor types, which is not be reported in other cancers previously. The further clarification of underlying molecular events would be helpful for understanding the role of S100A13 and HMGA1 in the progression of thyroid cancer.

\section{Conclusions}

In summary, this is the first report for the association between HMGA1 and S100A13 expression in the modulation of thyroid cancer growth and invasion. Those results would provide an essential insight into the effect of S100A13 on carcinogenesis of thyroid tumor, rending S100A13 to be potential biological marker for the diagnosis of thyroid cancer.

\section{Additional files}

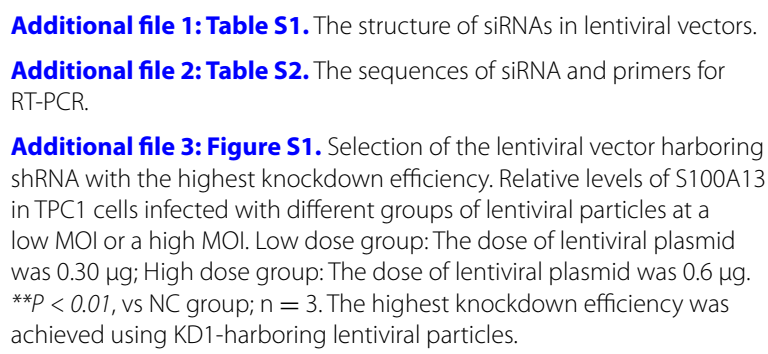

Additional file 3: Figure S1. Selection of the lentiviral vector harboring shRNA with the highest knockdown efficiency. Relative levels of S100A13 in TPC1 cells infected with different groups of lentiviral particles at a low MOl or a high MOI. Low dose group: The dose of lentiviral plasmid was $0.30 \mu \mathrm{g}$; High dose group: The dose of lentiviral plasmid was $0.6 \mu \mathrm{g}$. ${ }^{* *} P<0.01$, vs NC group; $n=3$. The highest knockdown efficiency was achieved using KD1-harboring lentiviral particles.

Additional file 4: Figure S2. Lentivirus-mediated S100A13 knockdown was utilized to detect the effect on cellular proliferation with MTT (a) and colony formation assays (b) in SW579 cell.

Additional file 5: Figure S3. Lentivirus-mediated S100A13 knockdown was utilized to detect the effect on migration capability with scratchwound assays in TPC1 cell.

Additional file 6: Figure S4. S100A13 increase the mRNA levels of HMGA1 and SNAIL in TPC-1 cells. The GV219/S100A13 plasmid was introduced into TPC-1 cells for $48 \mathrm{~h}$, and the mRNA levels of HMGA1 and SNAIL were assessed by Q-PCR. Average values of three independent experiments are shown, error bar indicates \pm s.d. ${ }^{* *} p<0.05$.

Additional file 7: Figure S5. S100A13 increase the promoter activities of HMGA1 and SNAIL in TPC-1 cells. The PGL.10/ HMGA1 and PGL.10/ SNAIL were co-transfected with or without GV219/ S100A13 plasmid into TPC-1 cells. Average values of three independent experiments are shown, error bar indicates \pm s.d. ${ }^{*} p<0.05,{ }^{* *} p<0.01$.

\section{Authors' contributions}

JZ, XK, SC carried out the molecular studies and cellular assays. CL and YC carried out nude mice xenografts assays. QZ and JY carried out the immunoassays and performed the statistical analysis. JZ and GW participated in the design of the study and draft the manuscript. XZ and RC helped to design the study. All authors read and approved the final manuscript. 


\section{Author details}

${ }^{1}$ Institute of Clinical Medicine, The First Affiliated Hospital of University of South China, 421001 Hengyang, Hunan, People's Republic of China. ${ }^{2}$ Department of Metabolism and Endocrinology, The First People's Hospital of Chenzhou, Luojiajing Road, 102, 423000 Chenzhou, Hunan, People's Republic of China. ${ }^{3}$ Department of Metabolism and Endocrinology, The Second Affiliated Hospital of University of South China, 421001 Hengyang, Hunan, People's Republic of China. ${ }^{4}$ Department of Metabolism and Endocrinology, The First Affiliated Hospital of University of South China, 421001 Hengyang, Hunan, People's Republic of China.

\section{Acknowledgements}

This work is supported by projects from the National Natural Science Foundation of People's Republic of China (Grant No. 31200573, 81172542), Hunan Provincial Natural Science Foundation of China (12JJ3116, 13JJ6051), and The Health Department of Hunan Province (B2014-176).

\section{Competing interests}

The authors declare that they have no competing interests.

Received: 2 September 2015 Accepted: 2 January 2016

Published online: 23 March 2016

\section{References}

1. Dinarello CA. Interleukin-1, interleukin-1 receptors and interleukin-1 receptor antagonist. Int Rev Immunol. 1998;16:457-99.

2. Maini RN, Taylor PC. Anti-cytokine therapy for rheumatoid arthritis. Annu Rev Med. 2000:51:207-29.

3. Kawaguchi Y, Nishimagi E, Tochimoto A, Kawamoto M, Katsumata Y, Soejima $M$, et al. Intracellular IL-1a-binding proteins contribute to biological functions of endogenous IL-1a in systemic sclerosis fibroblasts. Proc Nat Acad Sci USA. 2006;103:14501-6.

4. Cao R, Yan B, Yang H, Zu X, Wen G, Zhong J. Effect of human S100A13 gene silencing on FGF-1 transportation in human endothelial cells. J Formos Med Assoc. 2010;109:632-40.

5. Mohan SK, Yu C. The IL1a-S100A13 heterotetrameric complex structure: a component in the non-classical pathway for interleukin 1 a secretion. J Biol Chem. 2011;286:14608-17.

6. Hsieh HL, Schafer BW, Weigle B, Heizmann CW. S100 protein translocation in response to extracellular S100 is mediated by receptor for advanced glycation endproducts in human endothelial cells. Biochem Biophys Res Commun. 2004;316:949-59.

7. Massi D, Landriscina M, Piscazzi A, Cosci E, Kirov A, Paglierani M, et al. S100A13 is a new angiogenic marker in human melanoma. Mod Pathol. 2010;23:804-13.

8. Azimi A, Pernemalm M, Frostvik Stolt M, Hansson J, Lehtio J, Egyhazi Brage $S$, et al. Proteomics analysis of melanoma metastases: association between S100A13 expression and chemotherapy resistance. Br J Cancer 2014;110:2489-95.

9. Paulitschke V, Haudek-Prinz V, Griss J, Berger W, Mohr T, Pehamberger H, et al. Functional classification of cellular proteome profiles support the identification of drug resistance signatures in melanoma cells. J Proteome Res. 2013;12:3264-76.

10. Pierce A, Barron N, Linehan R, Ryan E, O'Driscoll L, Daly C, et al. Identification of a novel, functional role for S100A13 in invasive lung cancer cell lines. Eur J Cancer. 2008;44:151-9.

11. Smirnov DA, Zweitzig DR, Foulk BW, Miller MC, Doyle GV, Pienta KJ, et al. Global gene expression profiling of circulating tumor cells. Cancer Res. 2005;65:4993-7.

12. Dinets A, Pernemalm M, Kjellin H, Sviatoha V, Sofiadis A, Juhlin CC, et al. Differential protein expression profiles of cyst fluid from papillary thyroid carcinoma and benign thyroid lesions. PLoS One. 2015;10:e0126472.

13. Martinez-Aguilar J, Clifton-Bligh R, Molloy MP. A multiplexed, targeted mass spectrometry assay of the $\mathbf{S 1 0 0}$ protein family uncovers the isoform-specific expression in thyroid tumours. BMC Cancer. 2015;15:199.

14. Reeves R. Nuclear functions of the HMG proteins. Biochim Biophys Acta. 2010;1799:3-14.
15. Resar $L M$. The high mobility group $A 1$ gene: transforming inflammatory signals into cancer? Cancer Res. 2010;70:436-9.

16. Fusco A, Fedele M. Roles of HMGA proteins in cancer. Nat Rev Cancer. 2007;7:899-910.

17. Fedele M, Fusco A. HMGA and cancer. Biochim Biophys Acta. 2010;1799:48-54

18. Shah SN, Cope L, Poh W, Belton A, Roy S, Talbot CC Jr, et al. HMGA1: a master regulator of tumor progression in triple-negative breast cancer cells. PLoS One. 2013;8:e63419.

19. Abe N, Watanabe T, Masaki T, Mori T, Sugiyama M, Uchimura H, et al. Pancreatic duct cell carcinomas express high levels of high mobility group I(Y) proteins. Cancer Res. 2000;60:3117-22.

20. Meyer B, Loeschke S, Schultze A, Weigel T, Sandkamp M, Goldmann T, et al. HMGA2 overexpression in non-small cell lung cancer. Mol Carcinog. 2007;46:503-11.

21. Masciullo V, Baldassarre G, Pentimalli F, Berlingieri MT, Boccia A, Chiappetta $\mathrm{G}$, et al. HMGA1 protein over-expression is a frequent feature of epithelial ovarian carcinomas. Carcinogenesis. 2003;24:1191-8.

22. Belton A, Gabrovsky A, Bae YK, Reeves R, lacobuzio-Donahue C, Huso DL, et al. HMGA1 induces intestinal polyposis in transgenic mice and drives tumor progression and stem cell properties in colon cancer cells. PLoS One. 2012;7:e30034.

23. Chiappetta G, Tallini G, De Biasio MC, Manfioletti G, Martinez-Tello FJ, Pentimalli $F$, et al. Detection of high mobility group I HMGI(Y) protein in the diagnosis of thyroid tumors: $\mathrm{HMGI}(\mathrm{Y})$ expression represents a potential diagnostic indicator of carcinoma. Cancer Res. 1998;58:4193-8.

24. Puca F, Colamaio M, Federico A, Gemei M, Tosti N, Bastos AU, et al. HMGA1 silencing restores normal stem cell characteristics in colon cancer stem cells by increasing p53 levels. Oncotarget. 2014;5:3234-45.

25. Karp JE, Smith BD, Resar LS, Greer JM, Blackford A, Zhao M, et al. Phase 1 and pharmacokinetic study of bolus-infusion flavopiridol followed by cytosine arabinoside and mitoxantrone for acute leukemias. Blood. 2011;117:3302-10.

26. Nelson DM, Joseph B, Hillion J, Segal J, Karp JE, Resar LM. Flavopiridol induces BCL-2 expression and represses oncogenic transcription factors in leukemic blasts from adults with refractory acute myeloid leukemia. Leuk Lymphoma. 2011;52:1999-2006.

27. Pegoraro S, Ros G, Piazza S, Sommaggio R, Ciani Y, Rosato A, et al. HMGA1 promotes metastatic processes in basal-like breast cancer regulating EMT and stemness. Oncotarget. 2013;4:1293-308.

28. Huang R, Huang D, Dai W, Yang F. Overexpression of HMGA1 correlates with the malignant status and prognosis of breast cancer. Mol Cell Biochem. 2015;404:251-7.

29. Lois C, Hong EJ, Pease S, Brown EJ, Baltimore D. Germline transmission and tissue-specific expression of transgenes delivered by lentiviral vectors. Science. 2002;295:868-72.

30. Zhong J, Cao RX, Liu JH, Liu YB, Wang J, Liu LP, et al. Nuclear loss of protein arginine $\mathrm{N}$-methyltransferase 2 in breast carcinoma is associated with tumor grade and overexpression of cyclin D1 protein. Oncogene. 2014;33:5546-58.

31. Zhong J, Cao RX, Zu XY, Hong T, Yang J, Liu L, et al. Identification and characterization of novel spliced variants of PRMT2 in breast carcinoma. FEBS J. 2012;279:316-35.

32. Cao RX, Tian LN, Wen F, Liu X, Zhong J, Wen GB. Overexpressing exogenous S100A13 gene and its effect on proliferation of human thyroid cancer cell line TT. Ai Zheng. 2008;27:822-7.

33. Donato R, Cannon BR, Sorci G, Riuzzi F, Hsu K, Weber DJ, et al. Functions of S100 proteins. Curr Mol Med. 2013;13:24-57.

34. Salama I, Malone PS, Mihaimeed F, Jones JL. A review of the $S 100$ proteins in cancer. Eur J Surg Oncol. 2008;34:357-64.

35. Garrett SC, Varney KM, Weber DJ, Bresnick AR. S100A4, a mediator of metastasis. J Biol Chem. 2006;281:677-80.

36. Krop I, Marz A, Carlsson H, Li X, Bloushtain-Qimron N, Hu M, et al. A putative role for psoriasin in breast tumor progression. Cancer Res. 2005;65:11326-34.

37. Maelandsmo GM, Florenes VA, Mellingsaeter T, Hovig E, Kerbel RS, Fodstad O. Differential expression patterns of S100A2, S100A4 and S100A6 during progression of human malignant melanoma. Int J Cancer. 1997;74:464-9.

38. Nipp M, Elsner M, Balluff B, Meding S, Sarioglu H, Ueffing M, et al. S100-A10, thioredoxin, and S100-A6 as biomarkers of papillary thyroid 
carcinoma with lymph node metastasis identified by MALDI imaging. J Mol Med (Berl). 2012;90:163-74.

39. Zhang L, Fogg DK, Waisman DM. RNA interference-mediated silencing of the $\mathrm{S} 100 \mathrm{~A} 10$ gene attenuates plasmin generation and invasiveness of Colo 222 colorectal cancer cells. J Biol Chem. 2004;279:2053-62.

40. Landriscina M, Bagala C, Mandinova A, Soldi R, Micucci I, Bellum S, et al. Copper induces the assembly of a multiprotein aggregate implicated in the release of fibroblast growth factor 1 in response to stress. J Biol Chem. 2001;276:25549-57.

41. Matsunaga $H$, Ueda H. Stress-induced non-vesicular release of prothymosin-alpha initiated by an interaction with $\mathrm{S100A13}$, and its blockade by caspase-3 cleavage. Cell Death Differ. 2010;17:1760-72.
42. Rani SG, Mohan SK, Yu C. Molecular level interactions of S100A13 with amlexanox: inhibitor for formation of the multiprotein complex in the nonclassical pathway of acidic fibroblast growth factor. Biochemistry. 2010;49:2585-92

43. Matsunaga $\mathrm{H}$, Ueda $\mathrm{H}$. Synergistic $\mathrm{Ca} 2+$ and $\mathrm{Cu} 2+$ requirements of the FGF1-S100A13 interaction measured by quartz crystal microbalance: an initial step in amlexanox-reversible non-classical release of FGF1. Neurochem Int. 2008;52:1076-85.

\section{Submit your next manuscript to BioMed Central} and we will help you at every step:

- We accept pre-submission inquiries

- Our selector tool helps you to find the most relevant journal

- We provide round the clock customer support

- Convenient online submission

- Thorough peer review

- Inclusion in PubMed and all major indexing services

- Maximum visibility for your research

Submit your manuscript at www.biomedcentral.com/submit
() Biomed Central 